\title{
Socioeconomic Inequalities in Colorectal Cancer Survival in Southern Spain: A Multilevel Population-Based Cohort Study
}

This article was published in the following Dove Press journal: Clinical Epidemiology

\author{
Miguel Angel Luque- \\ Fernandez iD ${ }^{1-3}$ \\ Daniel Redondo-Sánchez ${ }^{1,2}$ \\ Miguel Rodríguez- \\ Barranco 1,2,4 \\ Yoe-Ling Chang-Chan (iD) ${ }^{1,4}$ \\ Elena Salamanca- \\ Fernández ${ }^{1,2}$ \\ Olivier Núñez ${ }^{2,5}$ \\ Pablo Fernandez- \\ Navarro (iD ${ }^{2,5}$ \\ Marina Pollán ${ }^{2,5}$ \\ María-José Sánchez ${ }^{1,2,4,6}$ \\ 'Instituto de Investigación Biosanitaria de \\ Granada, Non-Communicable Disease \\ and Cancer Epidemiology Group, ibs. \\ GRANADA, University of Granada, \\ Granada, Spain; ${ }^{2}$ Biomedical Network \\ Research Centers of Epidemiology and \\ Public Health (CIBERESP), Madrid, Spain; \\ ${ }^{3}$ London School of Hygiene and Tropical \\ Medicine, Non-Communicable Disease \\ Epidemiology, London, UK; ${ }^{4}$ Andalusian \\ School of Public Health, Granada, Spain; \\ ${ }^{5}$ National Centre of Epidemiology, Health \\ Institute Carlos III (CNE-ISCIII), Madrid, \\ Spain; ${ }^{6}$ Department of Preventive \\ Medicine and Public Health, University of \\ Granada, Granada, Spain
}

Correspondence: Miguel Angel LuqueFernandez

Andalusian School of Public Health, Cuesta Del Observatorio, 4, Granada I8080, Spain

Email miguel-angel.luque@Ishtm.ac.uk
Background: Colorectal cancer (CRC) is the most frequently diagnosed cancer in Spain. Socioeconomic inequalities in cancer survival are not documented in Spain. We aim to study the association of socioeconomic inequalities with overall mortality and survival among CRC patients in southern Spain.

Methods: We conducted a multilevel population-based cohort study, including CRC cases for the period 2011-2013. The study time-to-event outcome was death, and the primary exposure was CRC patients' socioeconomic status assessed by the Spanish deprivation index at the census tract level. We used a mixed-effects flexible hazard model, including census tract as a random intercept, to derive overall survival estimates by deprivation.

Results: Among 3589 CRC patients and 12,148 person-years at risk (pyr), 964 patients died before the end of the follow-up. Mortality by deprivation showed the highest mortality rate for the most deprived group (96.2 per 1000 pyr, 95\% CI: 84.0-110.2). After adjusting for sex, age, cancer stage, and the area of residence, the most deprived had a $60 \%$ higher excess mortality risk than the less deprived group (excess mortality risk ratio: $1.6,95 \% \mathrm{CI}: 1.1-2.3$ ). Conclusions: We found a consistent association between deprivation and CRC excess mortality and survival. The reasons behind these inequalities need further investigation in order to improve equality cancer outcomes in all social groups.

Keywords: socioeconomic inequalities, colorectal cancer, survival, population-based epidemiology, epidemiological methods, multilevel

\section{Introduction}

In 2018, there were 9.6 million deaths caused by cancer worldwide, with cancer being the second leading cause of death. ${ }^{1}$ Mainly due to global aging, the incidence of cancer is expected to increase in the coming decades in Europe. The economic and societal costs of cancer are rising sharply, affecting the economic growth of western countries. ${ }^{2}$ Population-based cancer registries are an essential public health resource for epidemiological surveillance and cancer control. ${ }^{3}$ Cancer registries provide population-based cancer survival estimates as a general indicator of the natural history of the disease and the effectiveness of the health system. ${ }^{4}$ In northern European countries, cancer registries have a long tradition of using indices of deprivation to characterize cancer socioeconomic inequalities at a geographical level. $^{5}$

Socioeconomic inequalities in cancer survival are well documented worldwide. ${ }^{6-10}$ In the United Kingdom, cancer patients living in wealthier areas have higher survival 
than those living in more disadvantaged areas. ${ }^{11}$ However, in Spain, there are no documented socioeconomic inequalities in cancer survival.

Recently, a deprivation index was developed, based on the 2011 Spanish population census data. ${ }^{12}$ In Spain, colorectal cancer (CRC) is the most frequently diagnosed cancer with a high incidence in the elderly. ${ }^{13,14}$ Therefore, we aimed to study the association of socioeconomic inequalities with overall mortality and survival among CRC patients in the southern Spanish province of Granada, between 2011 and 2013.

\section{Patients and Methods}

\section{Study Design, Participants, Data, and Setting}

We conducted a multilevel population-based cohort study. The cohort was composed of all CRC cases identified between the period 2011-2013, including all those patients diagnosed during the same period and those who survived to 2011 from earlier cancer diagnosis in the southern Spanish province of Granada. ${ }^{15}$ Data were drawn from the Granada Cancer Registry, a population-based cancer registry in southern Spain launched in 1985 and covering a population of about 922,100 inhabitants. ${ }^{16}$ CRC corresponded to codes C18-C21 of the International Classification of Diseases 10th revision (ICD-10). ${ }^{17}$ Patients' follow-up started at the date of their CRC diagnosis up to the end of the study on December $31^{\text {st }}, 2013$. Patients who remained alive by the end of the study were censored.

\section{Variables}

\section{Outcome and Main Exposure}

The study outcome was CRC patient's vital status, and the main exposure was patients' socioeconomic status (SES) referred to the year 2011. Patients' SES was assessed by the SDI at the census tract level, developed by the social determinants of health working group of the Spanish Society of Epidemiology. ${ }^{12}$ The SDI was created using data from the Spanish 2011 census conducted by the Spanish National Statistics Institute. The index includes information from six indicators mainly related to employment and education: percentage of manual workers (employed or unemployed), percentage of occasional workers (employed or unemployed), and percentage of the population with insufficient education. We used the SDI as a proxy of patients' SES. It was measured as a standardized score (ie, mean: 0 , standard deviation: 1) with mean referred to the overall Spanish population. We computed the quintiles $(\mathrm{Q})$ of the SDI and contrasted Q5 (most deprived) vs Q1 (less deprived) in statistical analyses. $^{12}$

\section{Other variables}

We included patient's age, sex, and cancer stage at diagnosis in the analysis. Age at diagnosis was categorized into five age groups. The stage at diagnosis variable was defined as the combination of clinical and pathological TNM stages at diagnosis, based on the 7th edition of the TNM manual, ${ }^{18}$ and categorized into four groups.

The study was carried out in accordance with the principles of the Declaration of Helsinki. The Granada Cancer Registry complies with relevant national and European data protection and privacy regulations. The internal review board of the Andalusian School of Public Health and the ethics committee from the Department of Health of the Andalusian Regional Government approved the study (PI18/01593). The data are held by the Regional Government of Andalusia and the Andalusian Health Department.

\section{Statistical Analysis}

We described the overall cohort of CRC patients using counts and proportions and contrasted the differences in sex, age, and cancer stage between the less (Q1) and most deprived (Q5). We then computed the CRC mortality rates per 1000 person-years, the unadjusted mortality rate ratios, with $95 \%$ confidence intervals (CIs), and the tests for trend p-values for all the variables.

We used a flexible parametric hazard modelling approach consisting of restricted cubic spline-based hazard models with three degrees of freedom and two internal knots to derive unadjusted and adjusted excess mortality (EM) risk and cancer-specific relative survival probabilities by the quintiles of deprivation. ${ }^{19}$ We used as background mortality the information from the Spanish life tables and performed a complete case analysis. We used the scaled Schoenfeld residuals as a function of time in order to evaluate the presence of a time-dependent effect of the levels of deprivation and the rest of covariates. ${ }^{20}$

We fitted different models, including one variable at each time, to control for confounding (ie, models 1-3). The final model was adjusted for age, sex, and cancer stage, including the interaction between time and cancer stage (ie, fully adjusted model 4). From each model, we derived the excess mortality risk ratios (EMRRs) and 95\% confidence intervals (CIs). To account for the clustering 
effect at the census tract level, we fitted a multilevel mixedeffects hazard model. The model specification was the same as model 4, but the patient's census tract area of residence was included as a random intercept. ${ }^{21}$ We plotted the adjusted relative survival probabilities derived from model 4 for the levels of deprivation (Q5 vs Q1). We also computed and plotted the standardized restricted mean survival time for the most and less deprived CRC patients and its difference in time (years). ${ }^{22,23}$ Then, we plotted the adjusted relative survival probabilities by the quintiles of deprivation (Q5 vs Q1) standardized to the empirical distribution of sex and age at cancer diagnosis. ${ }^{24-26}$

In the sensitivity analysis, we assessed whether the SDI 2011 was correlated with the individual average of income in euros by census tract for the calendar year $2015 .{ }^{27} \mathrm{We}$ explored the differences between patients who survived to 2011 from earlier cancer diagnosis with those diagnosed between 2011 and 2013 and allowed for the delay entry of those patients diagnosed before 2011 by setting the study entry to the 01.01.2011. Finally, we explored different modelling specifications, including the interaction between the SDI and TNM stage, age, and sex.

We used Stata MP v.16.0 (StataCorp, College Station, Texas, US), including the user-written programs stpm2 v.1.7.0, standsurv v.0.44 and stmixed v.2.0.3 ${ }^{28,29}$ for statistical analyses (Supplementary File 1).

\section{Results}

Among 3589 CRC patients and 12,148 person-years at risk, 964 (26.9\%) died before the end of 2013. After a maximum follow-up time of 10-year, the overall mortality rate was 79.3 per 1000 person-years. Overall, $32 \%$ of CRC patients were $>75$ years old, and $59 \%$ were male. TNM cancer stages II and III were the most frequent, with approximately one-third of the cases for each group. TNM cancer stage was the only variable with missing information (ie, 5\%) (Table 1).

CRC mortality rates were higher among the most deprived (Q5), males, those with advanced age (ie, $>75$ years), and patients with stage IV disease (ie, TNM stage IV mortality rate: 332.5 per 1000 person-years). The most deprived CRC patients (Q5) showed the highest mortality rate compared with the other quintiles of deprivation (ie, 96.2 per 1000 person-years, 95\% CI: 84.0-110.2) and four times higher mortality rate than the less deprived (Q1) (ie, mortality rate ratio: $1.4,95 \%$ CI: $1.1-1.7)$. There was evidence of an increased mortality risk across the levels
Table I Vital Status at 10 Years, Age, Sex, and TNM Cancer Stage at Cancer Diagnosis Among Colorectal Cancer Patients in Granada, Between 20II and 2013, n = 3,589

\begin{tabular}{|l|l|l|}
\hline Variables & & n (\%) \\
\hline Vital status at I0 years & Alive & $2,617(73.1)$ \\
& Dead & $964(26.9)$ \\
\hline Age at diagnosis, years & & \\
& $<50$ & $265(7.4)$ \\
& $50-59$ & $529(14.7)$ \\
& $60-69$ & $953(26.5)$ \\
& $70-75$ & $695(19.4)$ \\
& $>75$ & $1,147(32.0)$ \\
\hline Sex & & \\
& Male & $2,112(58.9)$ \\
& Female & I,477 (4I.I) \\
\hline TNM stage at diagnosis & & \\
& I & $64 I(17.9)$ \\
& II & I,I07 (30.8) \\
& III & I,082 (30.1) \\
& IV & $574(16.0)$ \\
& Missing & I85 (5.I) \\
\hline
\end{tabular}

of the categories of age, cancer stage, and deprivation (ie, test for trend $\mathrm{p}$-value $<0.001$ ) (Table 2).

Supplementary Table 1 shows CRC vital status at 10 years, sex, age and TNM cancer stage at diagnosis by deprivation (ie, Q1 and Q5 quintiles of deprivation). There was no evidence of a difference in proportions of sex and cancer stage by deprivation. However, most deprived CRC patients were older (ie, Q5 and $>75$ : $37.2 \%$ vs Q1 and $>75: 28.5 \%$ ) and showed a higher proportion of mortality at 10 years (ie, Q5: $30.7 \%$ vs Q1: 24.2\%).

Overall, multivariate-adjusted models showed higher EMRRs among the most deprived CRC patients compared with the less deprived. After adjustment for sex, age, TNM cancer stage at diagnosis, and accounting for patient's area of residence (ie, model 5) the most deprived CRC patients showed a $60 \%$ higher EM compared with the less deprived patients (ie, EM: 1.6, 95\% CI: 1.1-2.3). The variability (ie, variance) of CRC EM explained by the census tract was of 0.78 (95\% CI: 055-1.11) (Table 3).

Figure 1A shows the standardized relative survival probability by quintiles of deprivation (Q5 vs Q1). The estimated standardized relative survival probability at 10 years for the less deprived group was 0.69 (95\% CI: $0.66-0.73)$, and for 
Table 2 Ten-Year Overall Mortality Rate and Mortality Rate Ratios by Sociodemographic Characteristics, TNM Cancer Stage at Diagnosis, and Quintiles of Deprivation Among Colorectal Cancer Patients in Granada, Between 20II and 20I3, n = 3,589

\begin{tabular}{|c|c|c|c|c|}
\hline Variables & Deaths/Pyr & Mortality Rate per I 000 pyr $(95 \% \mathrm{Cl})$ & Mortality Rate Ratio (95\% Cl) & p-value \\
\hline Sex & & & & $<0.001$ \\
\hline Male & $602 / 6,878$ & $87.5(80.8-94.8)$ & Ref. & \\
\hline Female & $362 / 5,270$ & $68.7(62.0-76.1)$ & $0.8(0.7-0.9)$ & \\
\hline Age at diagnosis, years & & & & $<0.00 I^{*}$ \\
\hline$<50$ & $40 / 1,024$ & $39.1(28.7-53.3)$ & Ref. & \\
\hline $50-59$ & $74 / 1,997$ & $37.0(29.5-46.5)$ & $0.9(0.6-1.4)$ & \\
\hline $60-69$ & $163 / 3,609$ & $45.2(38.7-52.7)$ & $1.2(0.8-1.6)$ & \\
\hline $70-75$ & $|86 / 2,63|$ & $70.7(6|.2-8| .6)$ & $1.8(1.3-2.5)$ & \\
\hline$>75$ & $501 / 2,886$ & $173.6(159.0-189.5)$ & $4.4(3.2-6.1)$ & \\
\hline TNM stage at diagnosis & & & & $<0.00 I^{*}$ \\
\hline I & $96 / 2,529$ & $38.0(31.1-46.4)$ & Ref. & \\
\hline ॥ & $215 / 4,215$ & $51.0(44.6-58.3)$ & $1.3(1.1-1.7)$ & \\
\hline III & $238 / 3,867$ & $61.5(54.2-69.9)$ & $1.6(1.3-2.1)$ & \\
\hline IV & $331 / 995$ & $332.7(298.6-370.3)$ & $8.6(7.0-11.0)$ & \\
\hline Quintiles of deprivation & & & & $<0.001 *$ \\
\hline QI (less deprived) & $178 / 2,569$ & $69.3(59.8-80.2)$ & Ref. & \\
\hline Q2 & $175 / 2,484$ & $70.5(60.7-81.7)$ & $1.0(0.8-1.2)$ & \\
\hline Q3 & $198 / 2,458$ & $80.6(70.1-92.6)$ & $1.2(0.9-1.4)$ & \\
\hline Q4 & $204 / 2,465$ & $82.8(72.1-94.9)$ & $1.2(1.0-1.5)$ & \\
\hline Q5 (most deprived) & $209 / 2,172$ & $96.2(84.0-110.2)$ & $1.4(1.1-1.7)$ & \\
\hline
\end{tabular}

Note: *Test for trend $p$-value.

Abbreviations: pyr, person-years; $\mathrm{Cl}$, confidence interval.

the most deprived was 0.63 (95\% CI: $0.57-0.70)$. Figure 1B shows the standardized mean survival times for the most and the less deprived CRC patients, and Figure 1C the survival gap in years as a function of time. The mean survival time at ten years was 7.6 years $(95 \% \mathrm{CI}: 7.1-8.0)$ for the most deprived CRC patients versus 8.0 years (95\% CI: 7.8-8.2) for the less deprived (Figure 1B). The survival gap increased over time. At the end of the 10-year follow-up, the most deprived CRC patients, on average, lived 0.43 years (158 days) less than the less deprived patients (mean survival difference Q5 vs Q1: -0.43 years, 95\% CI: [-0.78][-0.08]) (Figure 1C).

Figure 2 shows the adjusted relative survival probabilities for the most and less deprived CRC patients derived from model 5 and marginalized over the categories of sex and age. The most deprived patients showed lower survival probabilities than the less deprived for any combination of age and sex. Compared with men, women showed a smaller contribution to the survival gap between the most and less deprived groups.

In the sensitivity analysis, we found a strong association between the 2011 SDI and the average income per person by census tract for the calendar year 2015 (ie, Pearson correlation: $-0.74,95 \%$ CI: $[-0.74]-[-0.73]$ ) (Supplementary Figure 1). ${ }^{27}$ There was no evidence of non-proportionality of the baseline hazard for the levels of deprivation (ie, test for the scaled Schoenfeld residuals p-value $=0.706)($ Supplementary Figure 2$)$ and there was no evidence of an interaction between deprivation with age, sex, and TNM cancer stage (p-values 0.398, 0.480, and 0.385 , respectively). Furthermore, our results regarding the association between deprivation and EM among CRC were consistent with different models' specifications and allowing the delayed entry for those patients diagnosed before 2011 (ie, EMRR Q5 vs Q1: 1.3, 95\% CI: 1.0-2.3). Supplementary Table 2 shows the differences in the distribution of deprivation, age, sex, and TNM cancer stage among CRC patients who survived to 2011 from earlier cancer diagnosis with those diagnosed between 2011 and 2013. Both groups showed a similar distribution in the variables under study. Furthermore, in stratified sensitivity analysis assessing the consistency of the EM risk comparing the quintiles of deprivation Q5 vs Q1 for both groups, showed similar results (ie, EMRR $=1.4 ; 95 \%$ 
Table 3 Excess Mortality Risk by Deprivation Quintiles Adjusted for Sex, Age, TNM Cancer Stage at Diagnosis, and Census Tract Area in Granada, Between 2011 and 2013, $n=3,404$

\begin{tabular}{|c|c|c|c|c|c|}
\hline Variables & $\begin{array}{l}\text { Model I } \\
\text { EMRR }(95 \% \mathrm{Cl})\end{array}$ & $\begin{array}{l}\text { Model } 2 \\
\text { EMRR }(95 \% \mathrm{Cl})\end{array}$ & $\begin{array}{l}\text { Model } 3 \\
\text { EMRR }(95 \% \mathrm{Cl})\end{array}$ & $\begin{array}{l}\text { Model } 4 \\
\text { EMRR }(95 \% \mathrm{Cl})\end{array}$ & $\begin{array}{l}\text { Model } 5 \\
\text { EMRR }(95 \% \mathrm{Cl})\end{array}$ \\
\hline $\begin{array}{l}\text { Quintiles of deprivation } \\
\text { Q1 } \\
\text { Q2 } \\
\text { Q3 } \\
\text { Q4 } \\
\text { Q5 }\end{array}$ & $\begin{array}{l}\text { Ref. } \\
1.0(0.7-1.4) \\
1.2(0.9-1.7) \\
1.1(0.8-1.6) \\
1.6(1.2-2.1)\end{array}$ & $\begin{array}{l}\text { Ref. } \\
1.0(0.7-1.4) \\
1.2(0.9-1.7) \\
1.2(0.8-1.5) \\
1.6(1.2-2.1)\end{array}$ & $\begin{array}{l}\text { Ref. } \\
0.9(0.7-1.3) \\
1.2(0.9-1.6) \\
1.1(0.8-1.6) \\
1.4(1.1-1.9)\end{array}$ & $\begin{array}{l}\text { Ref. } \\
0.8(0.8-1.5) \\
1.4(1.0-1.8) \\
1.3(0.9-1.7) \\
1.5(1.1-2.0)\end{array}$ & $\begin{array}{l}\text { Ref. } \\
1.2(0.8-1.8) \\
1.5(1.0-2.1) \\
1.4(1.0-2.0) \\
1.6(1.1-2.3)\end{array}$ \\
\hline $\begin{array}{l}\text { Sex } \\
\text { Female } \\
\text { Male }\end{array}$ & & $\begin{array}{l}\text { Ref. } \\
1.2(1.0-1.4)\end{array}$ & $\begin{array}{l}\text { Ref. } \\
1.2(1.0-1.4)\end{array}$ & $\begin{array}{l}\text { Ref. } \\
\text { I.I }(0.9-1.4)\end{array}$ & $\begin{array}{l}\text { Ref. } \\
1.2(1.0-1.5)\end{array}$ \\
\hline $\begin{array}{l}\text { Age at diagnosis } \\
\quad<50 \\
50-59 \\
60-69 \\
70-75 \\
>75\end{array}$ & & & $\begin{array}{l}\text { Ref. } \\
0.8(0.5-1.3) \\
0.9(0.6-1.3) \\
1.1(0.7-3.6) \\
2.5(1.8-3.6)\end{array}$ & $\begin{array}{l}\text { Ref. } \\
I . I(0.7-1.7) \\
1.0(0.7-1.5) \\
1.4(0.8-2.0) \\
3.1(2.1-4.4)\end{array}$ & $\begin{array}{l}\text { Ref. } \\
1.2(0.7-1.8) \\
1.2(0.7-1.8) \\
1.5(0.9-2.3) \\
4.0(2.7-6.1)\end{array}$ \\
\hline $\begin{array}{l}\text { TNM stage at diagnosis } \\
\text { I } \\
\text { II } \\
\text { III } \\
\text { IV }\end{array}$ & & & & $\begin{array}{l}\text { Ref. } \\
2.8(1.1-7.1) \\
4.5(1.7-11.60) \\
32.7(13.5-79.7)\end{array}$ & $\begin{array}{l}\text { Ref. } \\
2.4(1.0-6.0) \\
4.4(1.8-10.4) \\
44.7(18.9-105.9)\end{array}$ \\
\hline $\begin{array}{l}\text { Census tracts } \\
\text { Variance }(95 \% \mathrm{Cl})\end{array}$ & & & & & $0.78(0.55,1.11)$ \\
\hline
\end{tabular}

Notes: Model I: univariate excess mortality by quintiles of deprivation. Model 2: bivariate excess mortality by deprivation adjusted for sex. Model 3: multivariate excess mortality by deprivation adjusted for sex and age at diagnosis in categories. Model 4: multivariate excess mortality by deprivation adjusted for sex, age and cancer TNM stage. Model 5: multilevel multivariate excess mortality by deprivation adjusted for sex, age and cancer TNM stage accounting for the census tract level area.

Abbreviations: EMRR, excess mortality risk ratio; $\mathrm{Cl}$, confidence interval.

CI: 0.8-2.3 among CRC patients who survived to 2011 from earlier cancer diagnosis, and $\mathrm{EMRR}=1.3 ; 95 \% \mathrm{CI}$ : 1.0-1.9 among those CRC patients diagnosed between 2011 and 2013).

\section{Discussion}

We found a consistent association between deprivation and CRC EM in Granada, southern Spain. Most deprived CRC patients showed a higher EM than less deprived patients. At the end of the 10-year follow-up, the most deprived CRC patients, on average, lived 158 days less than the less deprived ones.

Our results are in line with others in the European context, where several studies assessed CRC survival based on SES. ${ }^{30-43}$ In this regard, Fowler et $\mathrm{al}^{39}$ conducted a study in England concluding that 90-day probability of death rose with increasing deprivation. Accordingly, in West Scotland, deprivation was independently associated with poorer 5-year CRC excess hazard (HR: 1.25, 95\% CI: 1.03-1.51, p-value: 0.024$){ }^{30}$ and in the Northern Region of England, deprivation was a predictor of overall survival in patients with CRC. ${ }^{31}$ In Switzerland, Feller et al $^{34}$ observed a social gradient for later-stage CRC with adjusted odds ratios of 1.11 (95\% CI: $0.97-1.19)$ and 1.28 (95\% CI: $1 .-$ 08-1.50) for middle and low socioeconomic position compared to high socioeconomic position, respectively. Survival was lower in patients with CRC with a low socioeconomic position in the unadjusted model (HR: 1.18, 95\% CI: 1.07-1.30). Moreover, CRC survival by SES was explored in the Swedish Rectal Cancer Registry, ${ }^{41}$ and their results evidenced that income was of particular importance in stage III disease. Other epidemiological studies showed socioeconomic association with CRC screening ${ }^{32}$ and CRC risk. ${ }^{44}$ Therefore, socioeconomic inequalities are independently related to cancer mortality ${ }^{45}$ and have a strong impact on survival. ${ }^{46}$ 
A

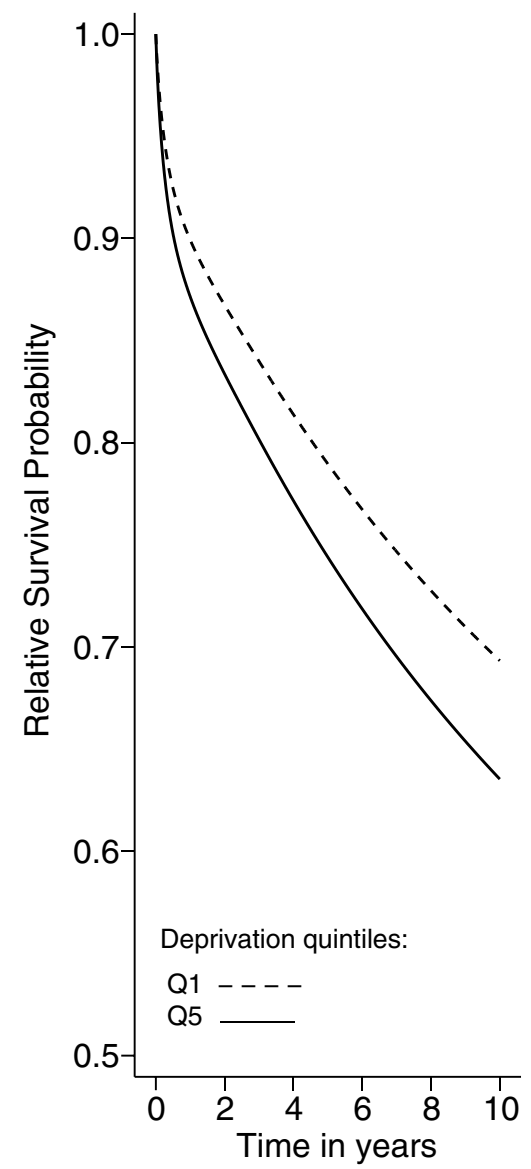

B

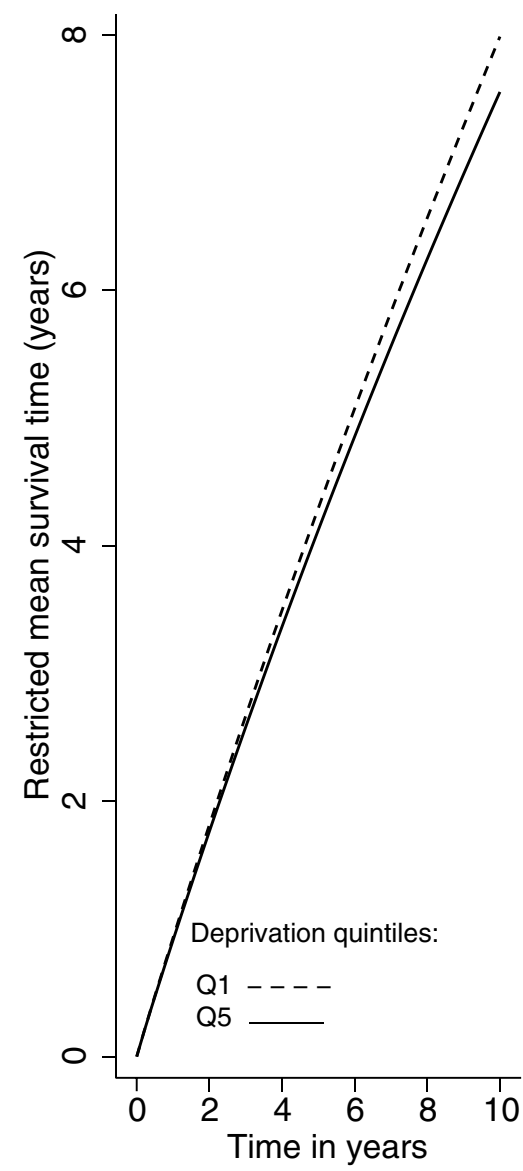

C

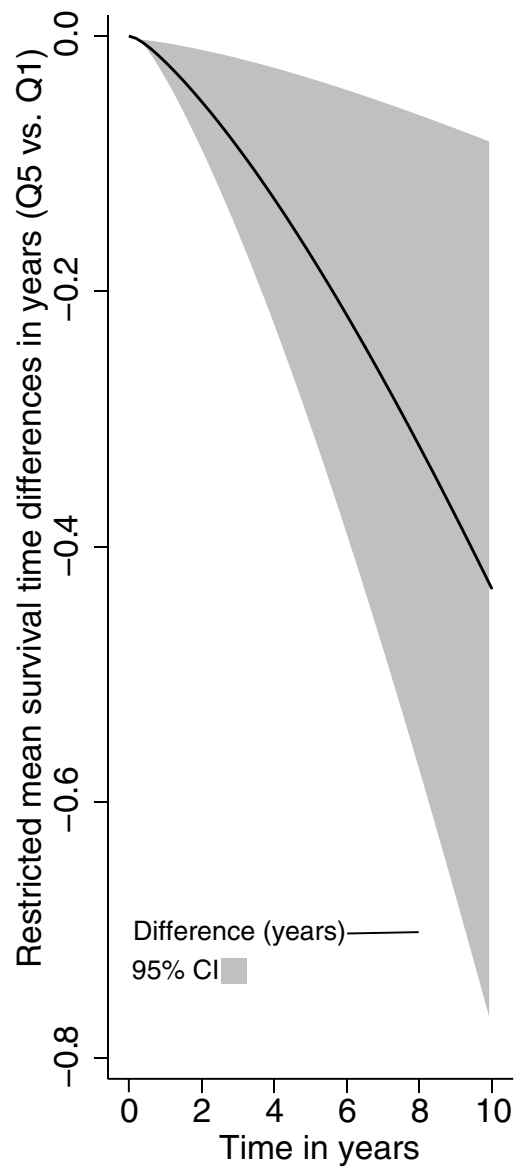

Figure I Relative survival probability, restricted mean survival time, and restricted mean survival time differences in years by levels of deprivation (Q5 vs QI) among colorectal cancer patients in Granada, between 201 I-2013, $\mathrm{n}=3582$.

Notes: (A) Relative survival probability by the quintiles of deprivation. Solid line: Q5 and dashed line: QI. (B) Restricted mean survival time in years by the quintiles of deprivation. Solid line: Q5 and dashed line: QI. (C) Restricted mean survival time differences in years by the quintiles of deprivation (Q5 vs QI). Solid line: differences, grey shaded area: $95 \% \mathrm{Cl}$.

There is evidence showing difficulties in accessing CRC screening among the most deprived patients. ${ }^{32}$ This has been shown to increase the probability of late cancer diagnosis (stage IV) or lower the probability of early cancer detection (stage I) among the most deprived CRC patients. ${ }^{47}$ However, our study showed no evidence of an association between TNM stage and deprivation. We argue that the absence of CRC screening in the province of Granada might have affected the survival gap that we found between the most and less deprived groups. However, several studies analysing the impact of SES in the participation of the screening programs found controversial results supporting the need for further evidence. ${ }^{48-}$ ${ }^{50}$ Despite the absence of screening in the province of Granada, the reasons behind these inequalities need further investigation in order to improve equality outcomes in all social groups.
In our study, we also found that women showed a smaller contribution to the survival gap between the most and less deprived groups. It aligns with the results of Antunes et $\mathrm{al}^{37}$ in Portugal where they found a pattern of worse 5- and 10-year net survival among male patients in the most deprived groups (survival gap between the most and least deprived groups: $-5 \%$ both at 5 and 10 years) but not such a clear pattern in female patients. It might be due to sex differences lifestyles such as drinking, smoking, and other cancer-related risk factors.

Furthermore, we found the highest 10-year EM and survival gap among older male patients ( $>75$ years). We argue that among older CRC male patients, socioeconomic inequalities can interact with other factors related to treatment decision-making (eg, health literacy, comorbidities, functional status, and social support). ${ }^{51,52}$ For instance, the marital status may play an essential role in cancer-survival 
Males
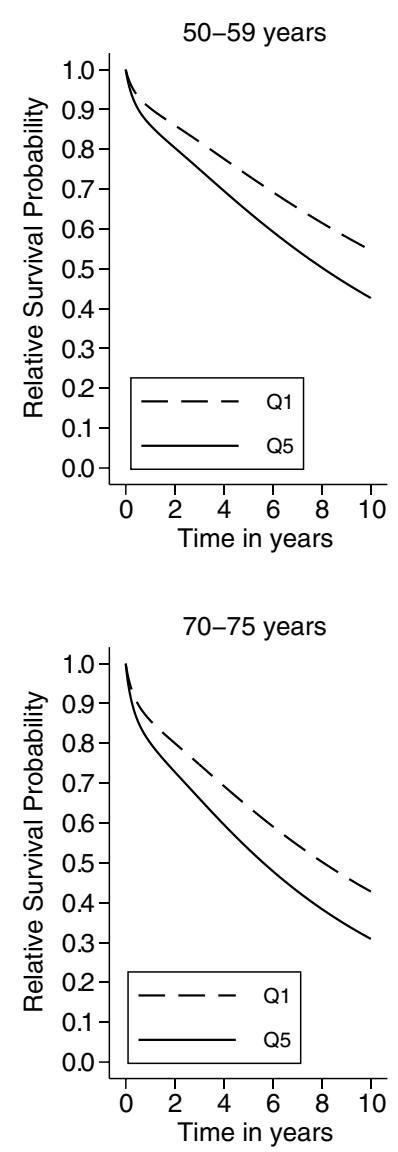

60-69 years
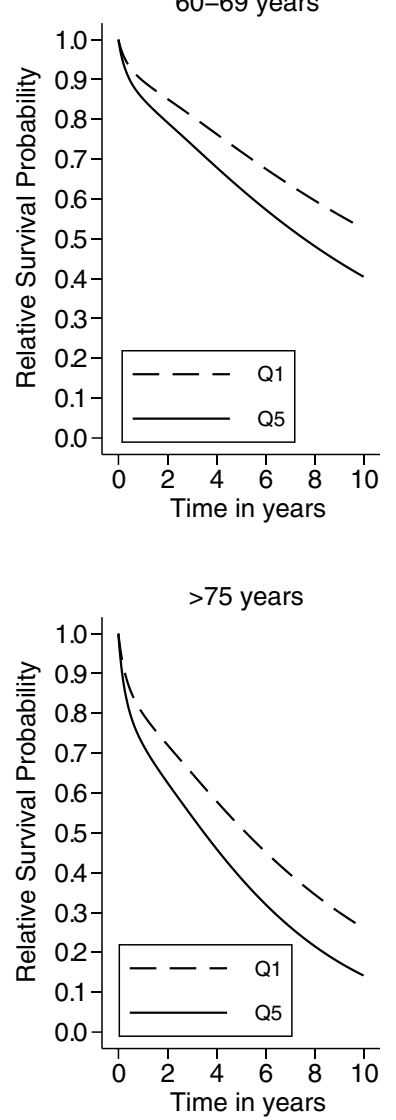

Females
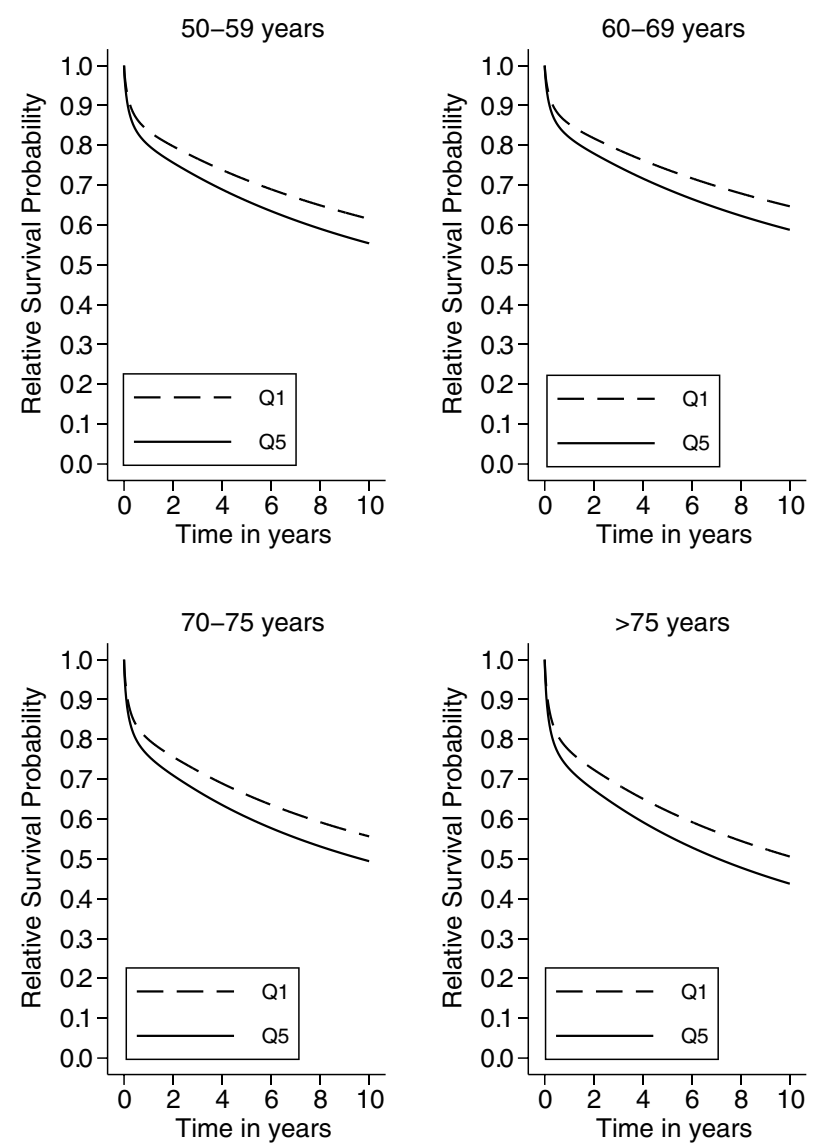

Figure 2 Sex-specific relative survival probability by deprivation (Q5 vs QI) and age at cancer diagnosis among colorectal cancer patients in Granada, between 20II-2013, $n=3,582$.

among older men as single compared to married people have elevated odds of being diagnosed at later stages ${ }^{34}$ and also have an increased risk of CRC death. ${ }^{41,53}$

The SDI is limited, as it did not include information regarding the average income by census tracts. It is mainly an index reflecting levels of deprivation by education and employment. However, in sensitivity analysis, we found a strong correlation between the SDI 2011 and the average income by census tract for the year 2015. Furthermore, the SDI is an ecological variable that we used as a proxy for individual SES status. Classically, SES in populationbased cancer research has been measured at an ecological level. However, it has led to mild associations between SES and cancer survival outcomes, mainly due to the ecological fallacy. ${ }^{54}$ This measurement bias might have affected the strength of the association we found towards the null, and further studies could try to include individual SES information. Our analytical approach partially addressed this issue, reducing modelling overdispersion due to the inclusion of the census tracts as a random intercept in the model. However, to compute the EM we used life tables stratified by age and sex, but not by deprivation, and it might have introduced some bias. Nevertheless, in sensitivity analysis results contrasting the overall and the relative setting did not show strong differences suggesting a homogeneous effect of deprivation on overall and cancer-specific mortality by deprivation. In order to assess the direction and the amount of this bias, further studies using life tables stratified by deprivation are needed in Spain.

Other limitations are related to the setting of time. All the analysis variables were referred at baseline (ie, the time of cancer diagnosis), including the quintiles of deprivation (exposure) for all cancer patients diagnosed between 2011 and 2013. However, for CRC patients who survived to 2011 from early cancer diagnosis, deprivation was not assessed at their cancer diagnosis. Thus, in sensitivity analysis allowing for the delayed entry to the 01.01.2011, we showed consistent results for the association between deprivation and EM. Furthermore, these patients showed a slightly lower 
proportion of TNM stage IV at diagnosis than CRC cases diagnosed between 2011 and 2013. However, in the stratified analysis, we show that the association between deprivation and EM remained consistent. Finally, our study is limited to only one Spanish province, but more studies are needed to generalize our results to the rest of the country.

In conclusion, there is a consistent survival gap between the most and less deprived CRC patients in Granada, southern Spain, characterized by a higher EM due to cancer in the most deprived group. These differences were more pronounced in males than females, patients with advanced age, and patients diagnosed with stage IV. Public health policies and preventive strategies are needed to reduce socioeconomic inequalities and the observed survival gap between the most and less deprived CRC patients in Granada, southern Spain.

\section{Data Sharing Statement}

The data are held by the Regional Government of Andalusia and the Andalusian Health Department. The code used in analyses is provided as a supplementary file.

\section{Author Contributions}

MALF designed the study, developed the analysis, and wrote the article. All authors contributed to data analysis, drafting or revising the article, gave final approval of the version to be published, and agree to be accountable for all aspects of the work.

\section{Funding}

M.A.L.F. received support from the Instituto de Salud Carlos III, Madrid, Spain (grant/award no. CP17/00206-EUFEDER). This work was supported by the Instituto de Salud Carlos III, Madrid, Spain [EU-FEDER-FIS PI-18/ 01593], the Consortium for Biomedical Research in Epidemiology and Public Health (CIBER en Epidemiología y Salud Pública), the Cancer Epidemiological Surveillance Subprogram (VICA) from the Instituto de Salud Carlos III, Madrid, Spain, and the Andalusian Department of Health [PI-0152/2017].

\section{Disclosure}

The authors have declared that no competing interests exist.

\section{References}

1. Ferlay J, Ervik M, Lam F, et al. Global Cancer Observatory: Cancer Today. Lyon; 2018.
2. World Bank. The Impact of Aging on Economic Growth. South East Europe Regular Economic Report No. 8S. Washington, DC: W.B.G. h.; 2015.

3. Parkin DM. The role of cancer registries in cancer control. Int $J$ Clin Oncol. 2008;13:102-111. doi:10.1007/s10147-008-0762-6

4. Coleman MP, Forman D, Bryant $\mathrm{H}$, et al. Cancer survival in Australia, Canada, Denmark, Norway, Sweden, and the UK, 1995-2007 (the international cancer benchmarking partnership): an analysis of population-based cancer registry data. Lancet. 2011;377 (9760):127-138. doi:10.1016/S0140-6736(10)62231-3

5. Department for Communities and Local Government. The English Indices of Deprivation 2015. 2015.

6. Shack LG, Rachet B, Brewster DH, Coleman MP. Socioeconomic inequalities in cancer survival in Scotland 1986-2000. Br J Cancer. 2007;97(7):999-1004. doi:10.1038/sj.bjc.6603980

7. Dalton SO, Kjær SK, Steding-Jessen M. Social inequality in incidence of and survival from cancer in a population-based study in Denmark, 1994-2003: summary of findings. Eur J Cancer. 2008;44 (14):2074-2085. doi:10.1016/j.ejca.2008.06.018

8. Gorey KM. Breast cancer survival in Canada and the USA: meta-analytic evidence of a Canadian advantage in low-income areas. Int $J$ Epidemiol. 2009;38(6):1543-1551. doi:10.1093/ije/ dyp193

9. Kogevinas M, Porta M. Socioeconomic Differences in Cancer Survival: A Review of the Evidence. IARC Sci Publ. 1997;138.

10. Woods L, Rachet B, Oncology MC-A of, 2005 U. Origins of socioeconomic inequalities in cancer survival: a review. 2006; Available from: https://academic.oup.com/annonc/article-abstract/17/1/5/ 160750. Accessed July 7, 2020.

11. Rachet B, Woods LM, Mitry E, et al. Cancer survival in England and Wales at the end of the 20th century. Br J Cancer. 2008;99 Suppl 1 (Suppl 1):S2-10.

12. Duque I, Domínguez-Berjón $M$, Cebrecos $A$, et al. Índice de privación en España por sección censal en 2011. Gac Sanit. 2020. doi:10.1016/j.gaceta.2019.10.008.

13. Red española de registros de cancer. Estimaciones de la incidencia del cáncer en España. 2019. Redecan. 2019;19:1-14.

14. Bray F, Ferlay J, Soerjomataram I, Siegel RL, Torre LA, Jemal A. Global cancer statistics 2018: GLOBOCAN estimates of incidence and mortality worldwide for 36 cancers in 185 countries. CA Cancer J Clin. 2018;68(6):394-424. doi:10.3322/caac.21492

15. Brenner H, Hakulinen T. Period versus cohort modeling of up-to-date cancer survival. Int J Cancer. 2008;122(4):898-904. doi:10.1002/ ijc. 23087

16. Instituto de Estadística y Cartografía de Andalucía. 2011 population census of Granada. Source: statistics and Cartography Institute of Andalusia. Available from: http://www.ieca.junta-andalucia.es/. Accessed February 3, 2020.

17. WHO. International statistical classification of diseases and related health problems - Tenth revision. 2016. Available from: https://icd. who.int/browse10/2016/en. Accessed February 3, 2020.

18. Egner JR, et al. AJCC Cancer Staging Manual 7th ed. JAMA. 2010;304(15):1726. doi:10.1001/jama.2010.1525

19. Royston P, Lambert PC Flexible parametric survival analysis using Stata: beyond the Cox model. Stata Press; 2011: 347. Available from: https:// www.crcpress.com/Flexible-Parametric-Survival-Analysis-Using-StataBeyond-the-Cox-Model/Royston-Lambert/p/book/9781597180795. Accessed September 10, 2019.

20. Grambsch PM, Therneau TM, Proportional hazards tests and diagnostics based on weighted residuals. Biometrika. 1994;81(3):515. doi:10.1093/biomet $/ 81.3 .515$

21. Crowther MJ, Look MP, Riley RD. Multilevel mixed effects parametric survival models using adaptive Gauss-Hermite quadrature with application to recurrent events and individual participant data meta-analysis. Stat Med. 2014;33(22):3844-3858. doi:10.1002/ $\operatorname{sim} .6191$ 
22. Royston P, Parmar MK, Restricted mean survival time: an alternative to the hazard ratio for the design and analysis of randomized trials with a time-to-event outcome. BMC Med Res Methodol. 2013;13 (1):152. doi:10.1186/1471-2288-13-152

23. Belot A, Ndiaye A, Luque-Fernandez M-A, et al. Summarizing and communicating on survival data according to the audience: a tutorial on different measures illustrated with population-based cancer registry data. Clin Epidemiol. 2019;11:53-65. doi:10.2147/CLEP.S173523

24. Robins JM, Hernán MA, Brumback B. Marginal structural models and causal inference in epidemiology. Epidemiology. 2000;11 (5):550-560. doi:10.1097/00001648-200009000-00011

25. Cole SR, Hernán MA. Adjusted survival curves with inverse probability weights. Comput Methods Programs Biomed. 2004;75 (1):45-49. doi:10.1016/j.cmpb.2003.10.004

26. Chang Y, Ryu S, Choi Y, et al. Metabolically healthy obesity and development of chronic kidney disease. Ann Intern Med. 2016;164 (5):305.

27. Estadística experimental. Tablas: Atlas de distribución de renta de los hogares.. Available from: https://www.ine.es/experimental/atlas/exp atlas_tab.htm. Accessed October, 30, 2019.

28. Crowther MJ. Multilevel mixed-effects parametric survival analysis: estimation, simulation, and application. Stata J. 2019;19(4):931-949. doi:10.1177/1536867X19893639

29. Royston P, Lambert PC, Royston PLP Flexible parametric survival analysis using Stata: beyond the Cox Model. Stata Press. 2011;347. Available from: https://www.stata.com/bookstore/flexible-parametricsurvival-analysis-stata/. Accessed December 10, 2018.

30. Oliphant R, Nicholson GA, Horgan PG, et al. Deprivation and colorectal cancer surgery: longer-term survival inequalities are due to differential postoperative mortality between socioeconomic groups. Ann Surg Oncol. 2013;20(7):2132-2139. doi:10.1245/s10434-0132959-9

31. Bharathan B, Welfare M, Borowski DW, et al. Impact of deprivation on short- and long-term outcomes after colorectal cancer surgery. $\mathrm{Br}$ J Surg. 2011;98(6):854-865. doi:10.1002/bjs.7427

32. von Wagner C, Good A, Wright D, et al. Inequalities in colorectal cancer screening participation in the first round of the national screening programme in England. Br J Cancer. 2009;101(Suppl): S60-3. doi:10.1038/sj.bjc.6605392

33. Pollock AM, Vickers N. Breast, lung and colorectal cancer incidence and survival in South Thames Region, 1987-1992: the effect of social deprivation. J Public Health Med. 1997;19(3):288-294. doi:10.1093/ oxfordjournals.pubmed.a024632

34. Feller A, Schmidlin K, Bordoni A, et al. Socioeconomic and demographic inequalities in stage at diagnosis and survival among colorectal cancer patients: evidence from a Swiss population-based study. Cancer Med. 2018;7(4):1498-1510. doi:10.1002/cam4.1385

35. McDaniel JT, Nuhu K, Ruiz J, Alorbi G. Global prevalence of Helicobacter pylori infection: systematic review and meta-analysis. Glob Health Promot. 2019;26(1):41-49. doi:10.1177/17579759 16686913

36. Syriopoulou E, Morris E, Finan PJ, Lambert PC, Rutherford MJ. Understanding the impact of socioeconomic differences in colorectal cancer survival: potential gain in life-years. Br J Cancer. 2019;120 (11):1052-1058. doi:10.1038/s41416-019-0455-0

37. Antunes L, Mendonça D, Bento MJ, Rachet B. No inequalities in survival from colorectal cancer by education and socioeconomic deprivation - a population-based study in the North Region of Portugal, 2000-2002. BMC Cancer. 2016;16:608. doi:10.1186/ s12885-016-2639-9

38. Hole DJ, McArdle CS. Impact of socioeconomic deprivation on outcome after surgery for colorectal cancer. Br J Surg. 2002;89 (5):586-590. doi:10.1046/j.1365-2168.2002.02073.x
39. Fowler H, Belot A, Njagi EN, et al. Persistent inequalities in 90-day colon cancer mortality: an English cohort study. $\mathrm{Br} J$ Cancer. 2017;117(9):1396-1404. doi:10.1038/bjc.2017.295

40. Breen N, Lewis DR, Gibson JT, Yu M, Harper S. Assessing disparities in colorectal cancer mortality by socioeconomic status using new tools: health disparities calculator and socioeconomic quintiles. Cancer Causes Control. 2017;28(2):117-125. doi:10.1007/s10552016-0842-2

41. Olsson LI, Granstrom F. Socioeconomic inequalities in relative survival of rectal cancer most obvious in stage III. World J Surg. 2014;38(12):3265-3275. doi:10.1007/s00268-014-2735-4

42. Paterson HM, Mander BJ, Muir P, Phillips HA, Wild SH. Deprivation and access to treatment for colorectal cancer in Southeast Scotland 2003-2009. Colorectal Dis. 2014;16(2):O51-7. doi:10.1111/ codi. 12442

43. Ramsay SE, Morris RW, Whincup PH, Papacosta AO, Lennon LT, Wannamethee SG. Time trends in socioeconomic inequalities in cancer mortality: results from a 35 year prospective study in British men. BMC Cancer. 2014;14(1):474. doi:10.1186/1471-2407-14-474

44. Kuznetsov L, Maier W, Hunger M, Meyer M, Mielck A. Regional deprivation in Bavaria, Germany: linking a new deprivation score with registry data for lung and colorectal cancer. Int J Public Health. 2012;57(5):827-835. doi:10.1007/s00038-012-0342-4

45. Marí-Dell'Olmo M, Gotsens M, Palència L, et al. Socioeconomic inequalities in cause-specific mortality in 15 European cities. J Epidemiol Community Health. 2015;69(5):432-441. doi:10.1136/ jech-2014-204312

46. Singh GK, Williams SD, Siahpush M, Mulhollen A. Socioeconomic, rural-urban, and racial inequalities in US cancer mortality. J Cancer Epidemiol. 2011;2011:1-27. doi:10.1155/2011/107497

47. García-Albéniz X, Hsu J, Hernán MA. The value of explicitly emulating a target trial when using real world evidence: an application to colorectal cancer screening. Eur J Epidemiol. 2017;32(6):495-500. doi:10.1007/s10654-017-0287-2

48. Hurtado JL, Bacigalupe A, Calvo M, et al. Social inequalities in a population based colorectal cancer screening programme in the Basque Country. BMC Public Health. 2015;15(1):1021. doi:10. 1186/s12889-015-2370-5

49. Burón A, Grau J, Andreu M, et al. Programa de Detección Precoz de Cáncer de Colon y Recto de Barcelona: indicadores de la primera ronda de un programa con participación de la farmacia comunitaria. Med Clin (Barc). 2015;145(4):141-146. doi:10.1016/j.medcli.2014. 05.027

50. Klabunde $\mathrm{CN}$, Djenaba AJ, King JB, et al. Vital signs: colorectal cancer screening test use-United States, 2012. Prev Heal Promot $C D C$ - MMWR. Available from. https:/www.ncbi.nlm.nih.gov/pmc/ articles/PMC4585592/. Accessed July 7, 2020.

51. Van Weert JCM, Van Munster BC, Sanders R, Spijker R, Hooft L, Jansen J. Decision aids to help older people make health decisions: a systematic review and meta-analysis. BMC Med Inform Decis Mak 2016;16(1):45. doi:10.1186/s12911-016-0281-8.

52. Luque-Fernandez MA, Redondo-Sanchez D, Lee SF, et al. Multimorbidity by patient and tumor factors and time-to-surgery among colorectal cancer patients in spain: a population-based study. Clin Epidemiol. 2020;12:31-40. doi:10.2147/CLEP.S229935

53. Donnelly C, Hart N, McCrorie AD, et al. Predictors of an early death in patients diagnosed with colon cancer: A retrospective case-control study in the UK. BMJ Open. 2019;9(6):e026057. doi:10.1136/bmjopen-2018-026057

54. Lokar K, Zagar T, Zadnik V. Estimation of the Ecological fallacy in the geographical analysis of the association of socio-economic deprivation and cancer incidence. Int J Environ Res Public Health. 2019;16(3):296. doi:10.3390/ijerph16030296 


\section{Publish your work in this journal}

Clinical Epidemiology is an international, peer-reviewed, open access, online journal focusing on disease and drug epidemiology, identification of risk factors and screening procedures to develop optimal preventative initiatives and programs. Specific topics include: diagnosis, prognosis, treatment, screening, prevention, risk factor modification,

\footnotetext{
Submit your manuscript here: https://www.dovepress.com/clinical-epidemiology-journal
}

systematic reviews, risk \& safety of medical interventions, epidemiology \& biostatistical methods, and evaluation of guidelines, translational medicine, health policies \& economic evaluations. The manuscript management system is completely online and includes a very quick and fair peer-review system, which is all easy to use. 